\title{
Surgical Strategies and Functional Outcome of Intramedullary Cervicomedullary Ependymoma
}

\author{
Xinbo $\mathrm{GE}^{1,2}$, Zhen WU ${ }^{1}$, Junting ZHANG ${ }^{1}$, Liwei ZHANG ${ }^{1}$ \\ ${ }^{1}$ Capital Medical University, Beijing Tiantan Hospital, Department of Neurosurgery; China National Clinical Research Center for Neurological \\ Diseases (NCRC-ND); Center of Brain Tumor, Beijing Institute for Brain Disorders; Beijing Key Laboratory of Brian Tumor, Beijing, China \\ ${ }^{2}$ Xingtai People's Hospital, Department of Neurosurgery, Hebei Province, China
}

\section{ABSTRACT}

AIM: To evaluate the surgical strategies and functional outcomes of intramedullary cervicomedullary ependymoma (ICE).

MATERIAL and METHODS: The authors retrospectively reviewed the clinical and imaging data of 28 ICE patients who underwent surgical resection, including 11 males and 17 females and the average age was 37.9 years (range:11-69 years). The modified McCormick grading system ( $\mathrm{mMG}$ ) was used to evaluate the neurological functions before surgery, at discharge and at long-term follow-up.

RESULTS: Gross total resections (GTRs) were performed in 21 patients (75.0\%), and subtotal resections (STRs) were achieved in the other 7 patients $(25.0 \%)$. An ill-defined tumor border was a significant factor leading to STR $(p=0.026)$. At discharge, the mMG improved in 11 patients (39.3\%), stabilized in 14 (50.0\%), and worsened in $3(10.7 \%)$. The 3 patients with deterioration were all in the STR Group and the neurological deterioration rate was significantly higher in the STR Group than that in the GTR Group ( $p=0.011)$. The follow-up period ranged from 9 to 77 months (mean $49.6 \pm 26.9$ months). Two patients $(7.1 \%)$ had tumor recurrence during this period. The long-term follow-up mMG was improved in 25 patients (89.3\%), stabilized in 3 (10.7\%), and no one worsened, compared with preoperative mMG.

CONCLUSION: GTR of ICE could be achieved in majority of patients, especially for those with well-defined tumor boundaries. GTR lead to a better outcome in the short term after surgery. A favorable functional outcome could be achieved for most ICE patients in the long term.

KEYWORDS: Ependymoma, Cervical spinal cord, Medulla oblongata, Intramedullary, Prognosis

\section{INTRODUCTION}

$\mathrm{E}$ pendymomas are uncommon central nervous system (CNS) neuroectodermal tumors and constitute approximately $2-8 \%$ of all primary CNS tumors and $30 \%-88 \%$ of primary spinal intramedullary tumors $(6,9,21$, 26). The majority of previous studies regarding ependymomas are either cerebral or intraspinal ependymomas, and intramedullary cervicomedullary ependymoma (ICE) is a really rare entity (15). Due to the location of the tumor, ICE may result in neurological dysfunction, such as motor weakness, respiration disorders, dysphagia, and so on.
Most ICEs are benign tumors that grow slowly, and usually lead to compression of the adjacent brain stem rather than infiltration. The plane of these tumors was relatively clear and gross-total resection (GTR) could be achieved in most cases. However, because of the tumor location, the surgical resection of the tumor could still result in disability even for experienced surgeons. Although radical resection is the goal of surgery, every effort should be made to preserve the functional status $(22,27)$.

Due to the rarity of this tumor, the treatment strategies, functional outcome and the prognostic factors are still unclear. 
Ge X. et al: Intramedullary Cervicomedullary Ependymoma

Therefore, the authors conducted this retrospective study to analyze the surgical strategies and functional outcomes of the ICE patients.

\section{MATERIAL and METHODS}

\section{Patient Population}

This study was approved by the Institutional Review Board of Beijing Tiantan hospital, Capital Medical University. The authors performed a retrospective study on 28 consecutive ICE patients, who were admitted in our institute between January 2009 and December 2014. All patients enrolled in this study underwent surgical resection and histological examination, and all patients were pathologically diagnosed with ependymoma (WHO Grade II) or anaplastic ependymoma (WHO Grade III). The definition of ICE was intramedullary ependymoma, which both rostrally involved the medulla oblongata and caudally involved the cervical cord.

According to the criteria, as shown in Table I, there were 11 males and 17 females enrolled in this series (ratio 0.65:1.00). Ages ranged from 11 to 69 years with an average of $37.9 \pm 13.4$ years. The clinical features, imaging findings, surgical treatment, complications and outcomes at short-term and long-term follow-up were analyzed.

\section{Clinical Evaluation}

Functional status was assessed based on the modified McCormick grading (mMG) system (Table II) preoperatively, at discharge (1-4 weeks after surgery), and at long-term followup (9-77 months after surgery) $(5,12,18)$. The patients were followed up by telephone, outpatient and inpatient interviews.

\section{Imaging Study}

All patients underwent contrast-enhanced T1-weighted magnetic resonance imaging (MRI) of the cervical spinal cord preoperatively, 1-4 weeks after surgery, 3 to 6 months after surgery, and annually thereafter. The imaging findings included tumor location, tumor volume, tumor boundary, and presence and location of syringomyelia. Tumor volume was defined as: greatest anteroposterior dimension $\times$ greatest mediolateral dimension $\times$ greatest craniocaudal dimension $\times 0.5$ (19). The tumor boundary was assessed according to preoperative T2-weighted and contrast-enhanced T1-weighted MR images. On T2-weighted MRI, we identified if there was a clear subarachnoid space between the tumor and cord; on contrast-enhanced T1-weighted MRI, we determined if there was a smooth contour line between the tumor and the cord. If one or two of the above two conditions were met, it was defined as a well-defined tumor boundary (Figures 1A-D, 2A$D, 3 A-D)$. If neither condition was met, it was considered as an ill-defined tumor boundary (Figure 4A-D) $(7,15)$. The length of syrinx was measured on sagittal T2-weighted MRI.

\section{Surgical Procedures}

All patients were microsurgically treated through a standard suboccipital midline approach with the lateral decubitus position. After laminectomy, the dura mater and the arachnoid membrane were opened with the assistance of microscope.
Then, a myelotomy was performed along the midline of the spinal cord. The plane between the tumor and the cord was carefully dissected (15). To prevent neurological deficits, intraoperative monitoring of evoked potentials was applied, including spinal cord somatosensory evoked potentials (SSEPs), motor-evoked potentials (MEPs), and brainstem auditory evoked potentials (BAEPs) (16). After tumor resection, the dura mater was closed and then laminae replacement was performed to avoid future spinal instability. The syrinx was not manipulated directly during the operation.

\section{Extent of Tumor Resection}

The extent of surgery was classified as GTR, subtotal resection (STR), or partial resection. GTR was defined as complete removal of the visible tumor under microscope and no evidence of remnant on postoperative contrast-enhanced T1-weighted MRI (Figures 1A-D, 2A-D, 3A-D). It was taken as STR when at least $80 \%$ of the tumor was removed (Figure $4 A-D)$. If less than $80 \%$ of the tumor was excised, it was considered as partial resection $(14,15)$.

\section{Statistical Analysis}

All statistical analyses were performed with SPSS (Windows version 18.0, IBM). Wilcoxon signed rank test was performed to compare the mMG before surgery, at discharge and at the last follow-up. Logistic regression analysis was done to study factors associated with STR, including gender, age, duration of symptoms, syrinx, tumor volume, and tumor border. Chisquare test for the $\mathrm{R} \times \mathrm{C}$ contingency tables was used to analyze the difference in neurological outcome between the GTR Group and the STR Group. Odds ratio with 95\% confidence interval $(\mathrm{Cl})$ was presented. A probability value $<0.05$ was considered statistically significant.

\section{RESULTS}

\section{Clinical Characteristics}

On admission, all patients presented with neurological deficits of variable severity. As shown in Table I, the main clinical symptoms included motor deficits in 14 patients (50.0\%), neck pain in $13(46.4 \%)$, sensory changes in 12 (42.9\%), headache in $6(21.4 \%)$, lower cranial nerve $(\mathrm{CN})$ deficits (dysphagia, hoarseness, and bucking) in 4 (14.3\%) and dizziness in 2 patients $(7.1 \%)$. Clinical progression was relatively slow, and the mean duration of symptoms was $14.2 \pm 19.2$ months (range: 1-72 months).

Neurologically, according to the mMG system, 1 patient (3.6\%) was categorized in Grade I, 8 (28.6\%) in Grade lb, 12 (42.9\%) in Grade II, 5 (17.9\%) in Grade III and 2 (7.1\%) in Grade IV (Table I).

\section{Radiological Features}

The mean of the tumor length was $5.5 \pm 4.8 \mathrm{~cm}$ (range: $1.0-22.0$ $\mathrm{cm}$ ), and the caudal end of the tumor ranged from cervical 1 (C1) to thoracic 4 (T4) (medium C2). The mean tumor volume was $9.9 \pm 11.5 \mathrm{~cm}^{3}$ (range: $0.3-49.5 \mathrm{~cm}^{3}$ ). Syrinx was observed in 15 patients (53.6\%) and the length of syrinx ranged from 1.0 $\mathrm{cm}$ to $15.0 \mathrm{~cm}$ (mean $7.3 \pm 4.5 \mathrm{~cm}$ ). Eighteen patients $(64.3 \%)$ 
presented with a well-defined tumor boundary and an illdefined tumor boundary was detected in the other 10 patients (36.2\%) (Table I).

\section{Surgery and Morbidity}

Overall, GTR was achieved in 21 patients (75.0\%) (GTR Group), STR was conducted in 7 patients (25.0\%) (STR Group), and no patient underwent partial resection. Out of the 7 patients who underwent STR, in 6 patients had an ill-defined tumor boundary and 1 patient lost SSEPs intraoperatively, which prevented GTR. Furthermore, the factors leading to STR were studied using logistic regression analysis, and results showed that an ill-defined tumor border was a significant factor $(p=0.026, O R=202.937,95 \% \mathrm{Cl}: 1.870,22022.498)$. The other factors were not significantly associated, including gender $(p=0.574)$, age $(p=0.115)$, duration of symptoms $(p=0.315)$, syrinx $(p=0.987)$, and tumor volume $(p=0.378)$.

Twenty-six patients had a benign ependymoma (WHO Grade II) and 2 patients had an anaplastic ependymoma (WHO Grade III) (7.1\%), demonstrated by pathological examinations. Neurological function impairment was observed in 16 patients
(42.1\%), including respiratory difficulty $(n=3,10.7 \%)$, lower cranial nerve function impairment $(n=3,10.7 \%)$, intracranial infection $(n=2,7.1 \%)$, pneumonia $(n=2,7.1 \%)$, and pneumothorax $(n=1,3.6 \%)$.

After surgery, tracheal intubation was routinely kept to prevent suffocation or respiratory failure in all patients. Intubation was removed in 25 patients $(89.3 \%)$ in $1.5 \pm 1.2$ days (range: 1-6 days). The other 3 patients (10.7\%) who had respiratory difficulty underwent tracheostomy and required ventilator assistance for 3, 30, and 41 days, respectively. All these patients improved and could breathe independently before discharge. The tracheostomies were closed at 17, 40, and 60 days after surgery, respectively. Besides, nasogastric feedings were performed in 6 patients $(21.4 \%)$ for $15.4 \pm 20.5$ days (range: 1-50 days) due to lack of cough reflex.

We recommended radiotherapy to patients with STR and anaplastic ependymomas. A total of 7 patients underwent postoperative adjuvant conventional radiotherapy, including 3 patients with STR, 2 patients with anaplastic ependymomas, and 2 patients with benign tumors and GTR.
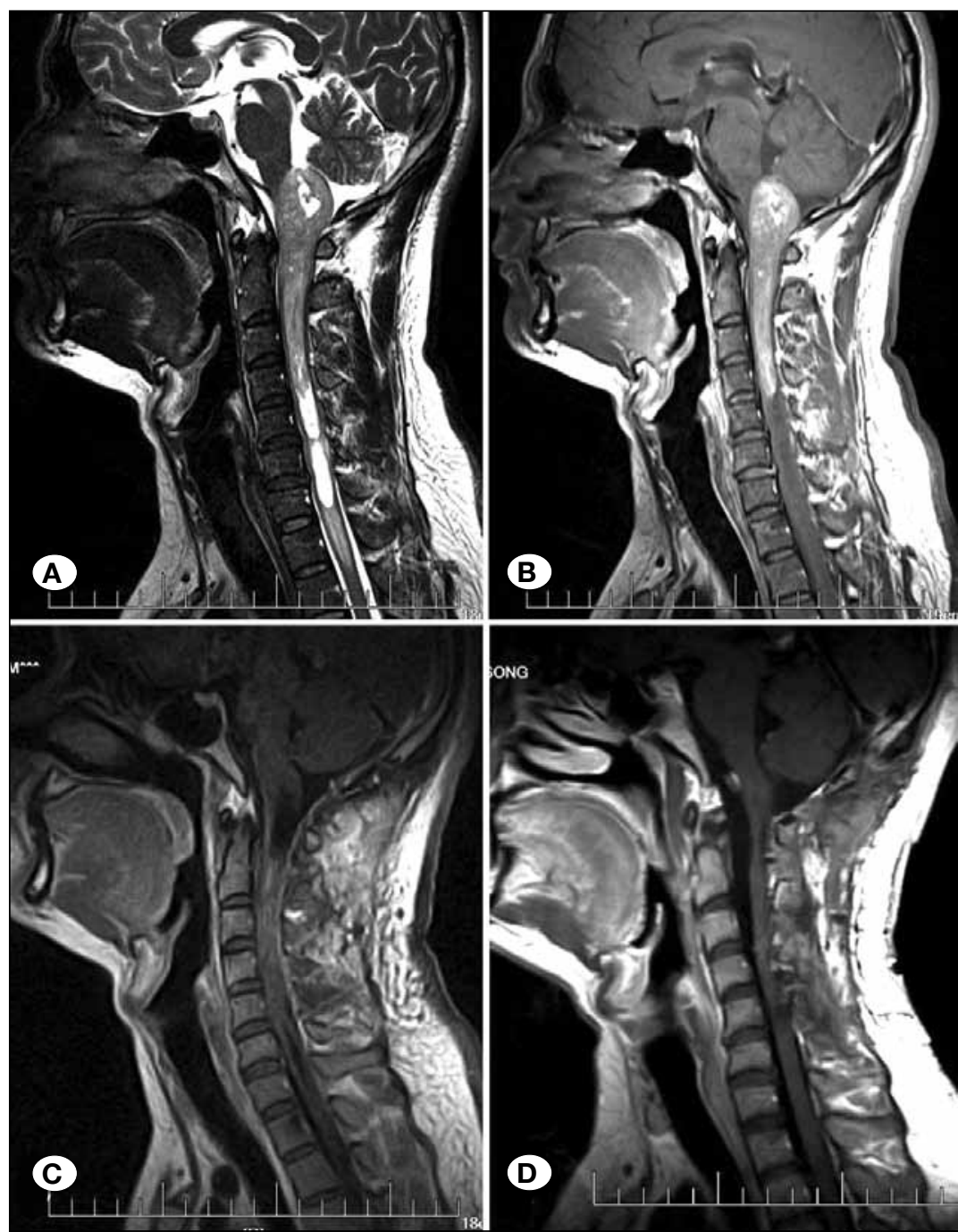

Figure 1: Pre- and postoperative MRI scans of patient No. 10.

Preoperative sagittal T2-weighted MRI (A) and T1-weighted imaging with contrast enhancement (B), showing the ependymoma from medulla oblongata to fourth cervical vertebra with a well-defined tumor boundary and a cervical syrinx. Postoperative MRI scans with contrast enhancement at 1 week $(\mathbf{C})$ and 3 years after operation (D), demonstrating complete resection of the lesion $(\mathrm{C})$ and no evidence of recurrence (D). The reduction of the syrinx could also be observed (D). 


\section{$\frac{\mathfrak{x}}{\mathrm{a}}$}

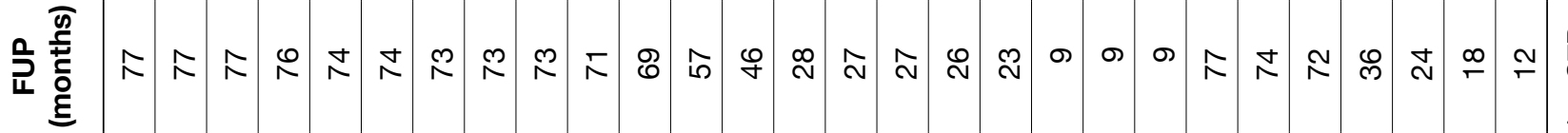

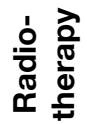

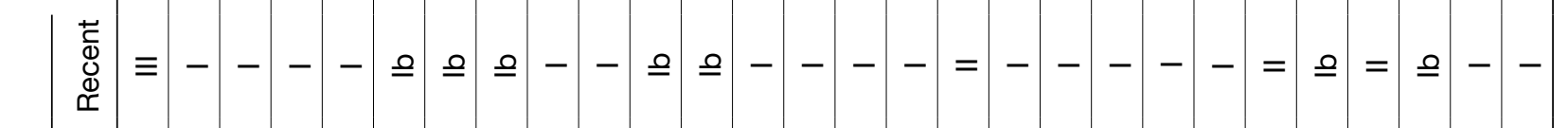

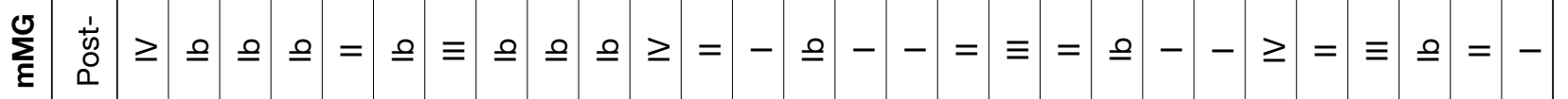

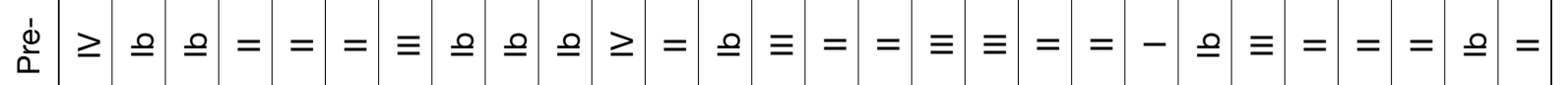

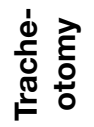

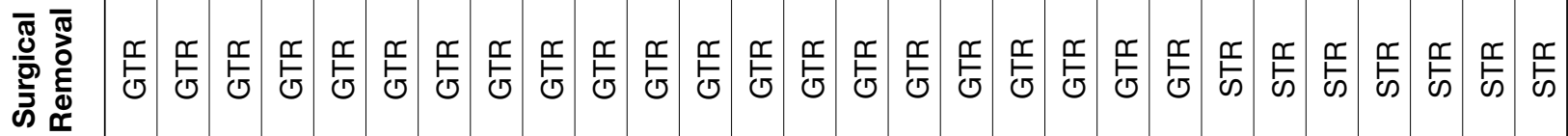

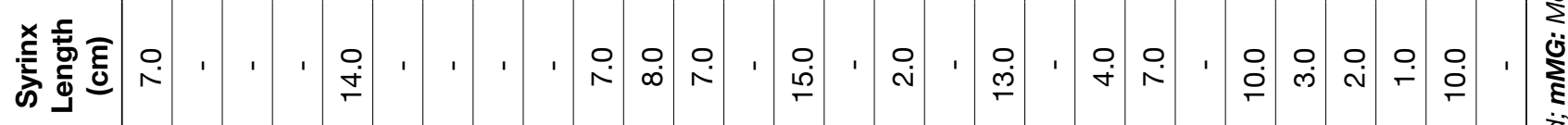

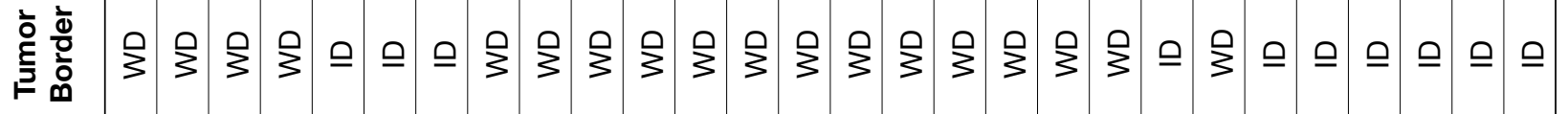

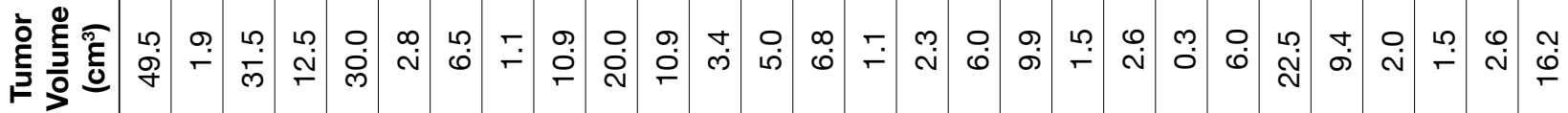

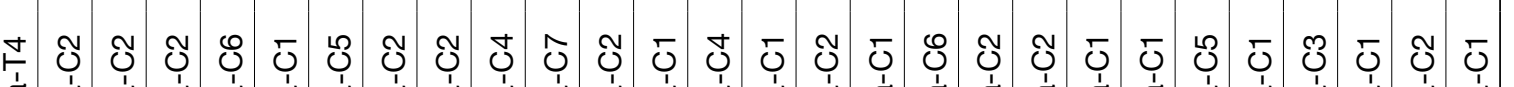

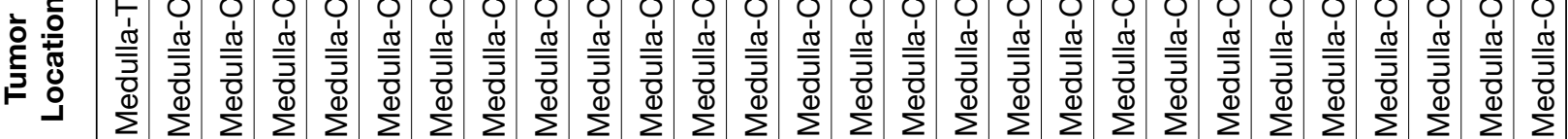

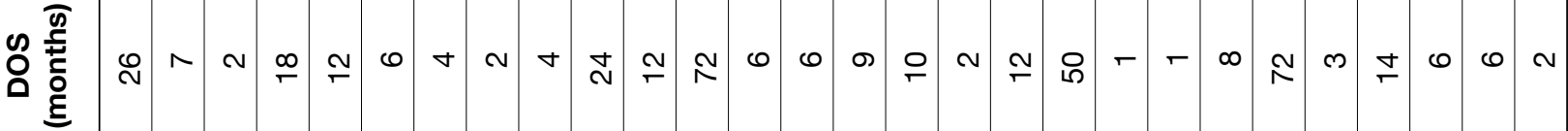

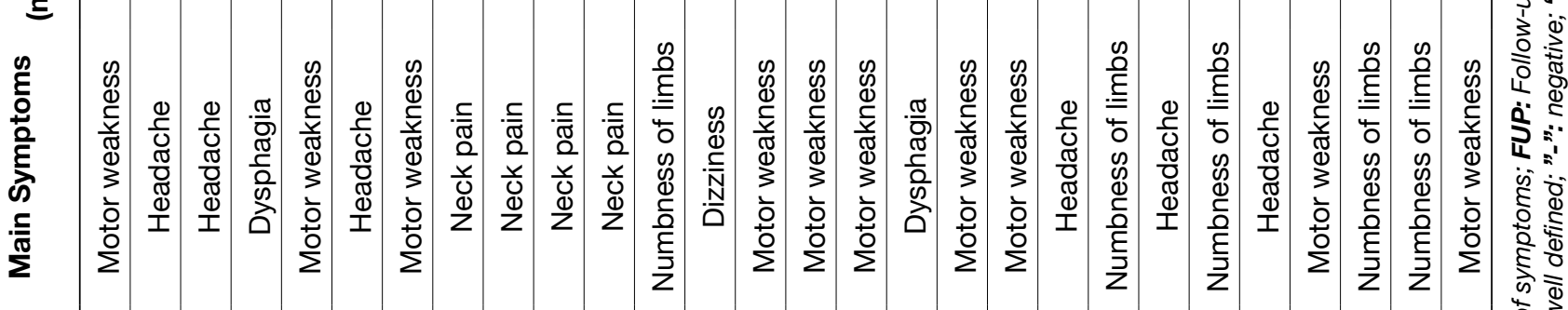

œ

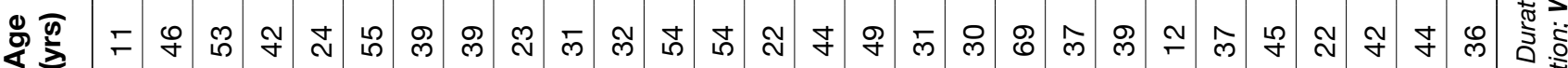

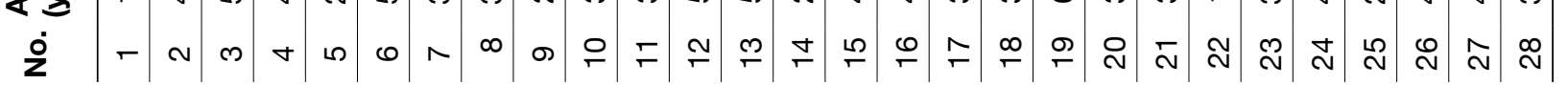




\section{Short-Term Outcomes}

As shown in Table I, compared to the preoperative mMG, the mMG at discharge improved in 11 patients (39.3\%), stabilized in $14(50.0 \%)$, and deteriorated in $3(10.7 \%)$. Wilcoxon signed rank test showed the $\mathrm{mMG}$ at discharge was significantly better than the preoperative $\mathrm{mMG}(\mathrm{p}=0.018)$. All the 3 patients with deterioration worsened 1 grade after surgery and they were all in the STR Group. And the neurological deterioration rate was significantly higher in the STR Group than that in the GTR Group ( $p=0.011$, by Fisher's exact test). Chi-square test showed the other factors were not significantly associated with neurological deterioration, including gender $(p=1.000)$, age $(p=1.000)$, syrinx $(p=0.226)$, and tumor length $(p=1.000)$.

Moreover, the transition of different preoperative symptoms was also studied, and the results were shown in Table III. At discharge, neck pain was relieved in all the 13 patients
$(100.0 \%)$, headache was relieved in 5 of the 6 patients $(83.3 \%)$, lower cranial nerve deficits was improved in 3 of the 4 patients $(75.0 \%)$, numbness of limbs and dizziness was relieved in $50.0 \%$ of the patients, and the improvement rate of motor deficits was $35.7 \%$. Therefore, the improvement rate of neck pain was significantly higher than that of motor deficits $(p=0.001$, by Fisher's exact test), and numbness of limbs $(p=0.005$, by Fisher's exact test). No significant difference was found between other symptoms. Only 3 patients with motor deficits deteriorated after surgery and the other symptoms were improved or stable. New onset of paresthesia, motor weakness, and ataxia occurred in $3(10.7 \%), 2(7.1 \%)$, and 1 (3.4\%) patient, respectively.

\section{Long-Term Outcomes}

The mean duration of follow-up was $49.6 \pm 26.9$ months (range: 9-77 months), and no patient died at the most recent follow-
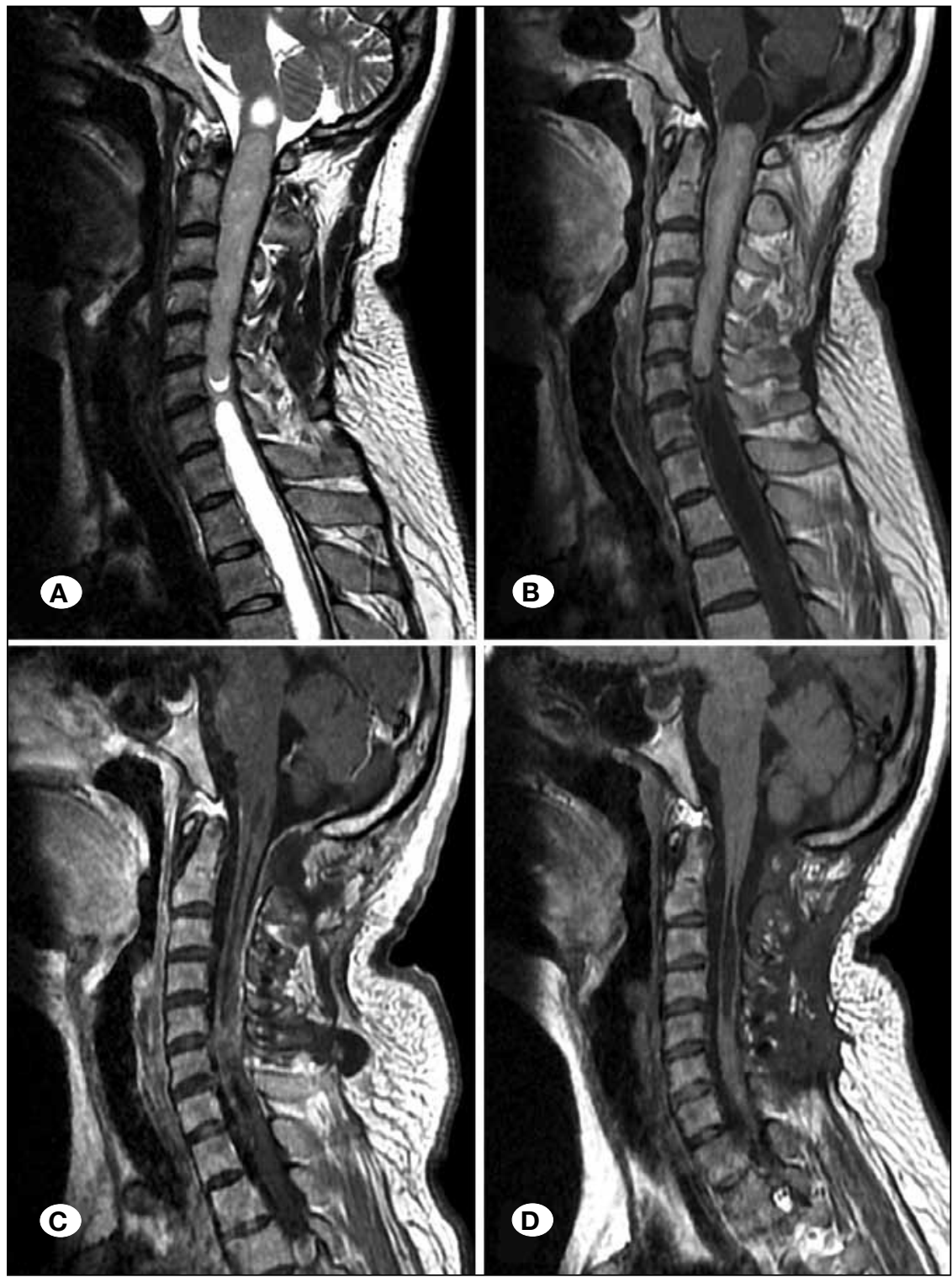

Figure 2: Pre- and postoperative MRI scans of patient No. 18.

Preoperative sagittal T2-weighted MRI (A) and T1-weighted imaging with contrast enhancement (B), showed the ependymoma from medulla oblongata to sixth cervical vertebra with a well-defined tumor boundary, and a cervicothoracic syrinx could also be observed. Postoperative MRI scans with contrast enhancement at 1 week (C) and 2 years (D), demonstrating complete resection of the lesion (C) and mild myelatrophy without recurrence, and reduction of the syrinx (D). 
up. Two (7.1\%) patients (No.1 and 5) had tumor recurrence after a mean period of 30 months, which were both local recurrence. These 2 patients were closely followed up at present and a second operation was not performed because they stayed clinically stationary. As shown in Table I, at the most recent follow-up, there were 17 Grade I patients $(60.7 \%)$, 7 Grade Ib patients (25.0\%), 3 Grade II patients (10.7\%), 1 Grade III patient (3.6\%), and no Grade IV patients. Compared to the preoperative $\mathrm{mMG}$, the $\mathrm{mMG}$ at long-term follow-up improved in 25 patients (89.3\%), stabilized in $3(10.7 \%)$, and no one worsened. The long-term neurological function was significantly better than that of the preoperative mMGs $(p<0.001$, by Wilcoxon signed rank test), and also significantly better than that of the mMGs at discharge $(p<0.001$, by Wilcoxon signed rank test), indicating that the operation could lead to better neurological functions in the long run.

The improvements in the symptoms detected at the most recent follow-up were detailed in Table III. In patients with preoperative motor dysfunction, neck pain, numbness of limbs, headache, lower cranial nerve deficits, and dizziness, the corresponding symptom improved in $78.6 \%, 100.0 \%, 75.0 \%$, $83.3 \%, 100.0 \%$, and $100.0 \%$ of the patients, respectively.

Moreover, although the syrinx was not directly manipulated during the operation, syrinx reduction could be observed in the follow-up MR images on all the 15 patients with syrinx (Figures 1A-D, 2A-D, 4A-D).

\section{DISCUSSION}

\section{Epidemiology and Clinical Features}

Ependymomas are an uncommon and relatively rare entity, which accounts for $2-8 \%$ of all primary CNS tumors and $30 \%-88 \%$ of primary spinal intramedullary tumors $(6,9,21$, 26). Ependymomas involving the medulla oblongata is rather rare. One report showed the average age at diagnosis is in the fourth decade of life (15), which is also confirmed by our results. Our study seemed to support that there might be a female predominance in ICE patients, with a male-to-female ratio of $0.65: 1.00$.

It is reported that the most common clinical manifestations was pain, followed by paresthesia, motor weakness, lower cranial nerve deficits, bladder dysfunction and headache (15). Our study revealed similar results, showing that motor weakness $(n=14,50.0 \%)$, neck pain $(n=14,46.4 \%)$ and numbness of limbs $(n=12,42.9 \%)$ are the most common symptoms. Although neck pain is not a specific manifestation for ICE patients and may occur in other diseases (cervical disc herniation, for example), we found it is important for ICE

Table II: Modified McCormick Grading Scale for Neurological Function*

\begin{tabular}{|c|c|c|c|c|c|c|c|}
\hline Grade & \multicolumn{7}{|l|}{ Grade Definition } \\
\hline $\mathrm{Ib}$ & \multicolumn{7}{|c|}{$\begin{array}{l}\text { Tired after walking several kilometers; running is impossible, or moderate sensorimotor deficit does not significantly } \\
\text { affect the involved limb; moderate discomfort in professional activity }\end{array}$} \\
\hline II & \multicolumn{7}{|c|}{$\begin{array}{l}\text { Presence of sensorimotor deficit affecting function of involved limb; mild to moderate gait difficulty; severe pain or } \\
\text { dysesthetic syndrome impairing patient's quality of life; still functions and ambulates independently }\end{array}$} \\
\hline IV & \multicolumn{7}{|c|}{ Severe deficit; requires wheelchair or cane/brace with bilateral upper extremity impairment; usually not independent } \\
\hline \multicolumn{8}{|c|}{ *From McCormick et al., 1990.} \\
\hline \multirow{2}{*}{\multicolumn{2}{|c|}{$\begin{array}{l}\text { Preoperative } \\
\text { Symptoms }\end{array}$}} & \multicolumn{3}{|c|}{ At discharge } & \multicolumn{3}{|c|}{ Recent } \\
\hline & & Improved (\%) & Stable (\%) & $\begin{array}{l}\text { Deteriorated } \\
\text { (\%) }\end{array}$ & Improved (\%) & Stable (\%) & $\begin{array}{l}\text { Deteriorated } \\
(\%)\end{array}$ \\
\hline \multicolumn{2}{|c|}{ Motor deficits $(n=14)$} & $5(35.7)$ & $6(42.9)$ & $3(21.4)$ & $11(78.6)$ & $3(21.4)$ & \\
\hline \multicolumn{2}{|c|}{ Neck pain $(n=13)$} & $13(100.0)$ & & & $13(100.0)$ & & \\
\hline \multicolumn{2}{|c|}{ Numbness $(n=12)$} & $6(50.0)$ & $6(50.0)$ & & $9(75.0)$ & $3(25.0)$ & \\
\hline \multicolumn{2}{|c|}{ Headache $(n=6)$} & 5 (83.3) & $1(16.7)$ & & $5(83.3)$ & $1(16.7)$ & \\
\hline \multicolumn{2}{|c|}{ Lower cranial nerve deficits $(n=4)$} & $3(75.0)$ & $1(25.0)$ & & $4(100.0)$ & & \\
\hline \multicolumn{2}{|c|}{ Dizziness $(n=2)$} & $1(50.0)$ & $1(50.0)$ & & $2(100.0)$ & & \\
\hline
\end{tabular}


patients because almost half of ICE patients had neck pain and it could be improved in all patients in a short term after surgery.

The majority of ICE are benign tumors and have a relatively long duration of illness $(1,2)$. In this series, the duration of illness ranged from 1-72 months with an average of $14.2 \pm 19.2$ months, which reflected the slow growth pattern of the tumor. No patient presented with acute symptoms suggestive of tumor hemorrhage.

\section{Surgical Management}

There is an agreement that surgical resection is the main treatment for spinal cord ependymomas, and the primary goal is GTR. Previous studies have shown that GTR is the most significant factor influencing the prognosis for spinal cord ependymomas and GTR was found to be superior to partial resection with radiation $(10,11,17,24,25)$. Meanwhile, it is also a general consensus to perform conservative STR rather than aggressive GTR, to prevent neurological function deficits (3, $13,14,20)$.
We agree with the above viewpoints. The primary goal of surgical resection of ICE is GTR without severe function deterioration. When GTR is safe to conduct, every effort should be made to achieve GTR. Intraoperatively, if infiltrating growth of the tumor and severe adhesion to the surrounding cord tissues is found, or the monitor shows abnormalities, STR should be considered rather than aggressive GTR. In our experience, with the improvement of microsurgical skills and the introduction of monitoring techniques such as SSEPs, MEPs and BAEPs, the removal of ICE has become associated with even lower morbidity and mortality rates, making GTR the primary goal in the treatment of ICE. The rate of GTR in treating spinal cord ependymomas in other series varies considerably from $50 \%$ to $92 \%(2,8,15,17,24)$. In our series, $75.0 \%$ of ICE underwent GTR.

Moreover, we found the significant factor leading to STR was an ill-defined tumor border on preoperative MRI $(p=0.026$, $\mathrm{OR}=202.937,95 \% \mathrm{Cl}: 1.870,22022.498)$. Of the 18 patients with a well-defined tumor border, 17 patients underwent GTR and only 1 patient had STR. Meanwhile, of the 10 patients with an ill-defined tumor border, 4 patients underwent GTR
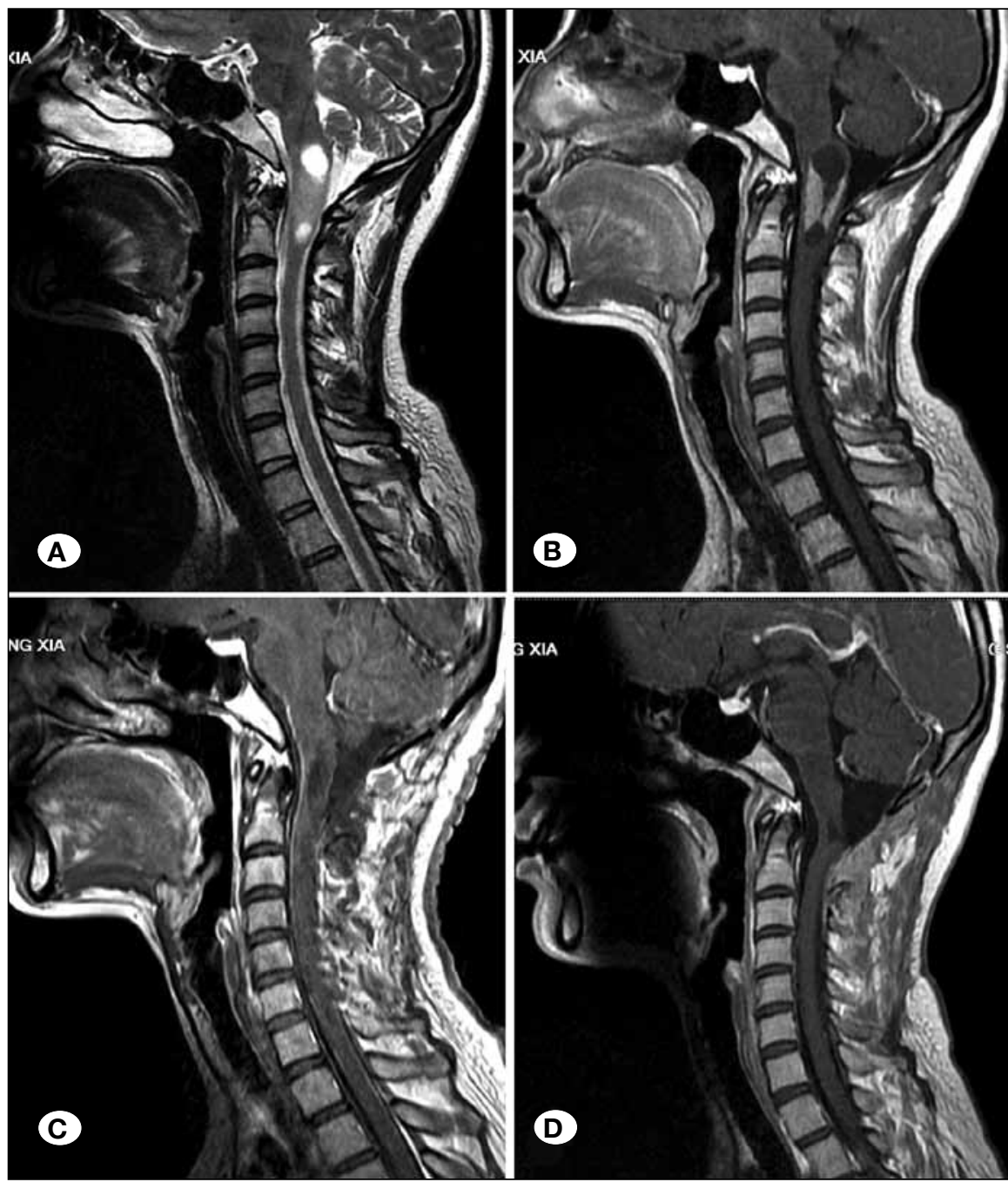

Figure 3: Pre- and postoperative MRI scans of patient No. 20.

Preoperative sagittal T2-weighted MRI (A) and T1-weighted imaging with contrast enhancement (B) showing the ependymoma from medulla oblongata rostrally to the second cervical vertebra caudally with a well-defined tumor boundary. Postoperative MRI scans with contrast enhancement at 1 week (C) and 6 months (D) illustrating total removal of the lesion $(C)$ and no recurrence (D). 
and 6 patients had STR. Therefore, the tumor border is a very important factor predicting if GTR could be achieved. In determining if the tumor boundary is clear, both T2-weighted MR images and contrast-enhanced T1-weighted MR images are important. A well defined boundary should meet at least one of the following two conditions: on T2-weighted MR images, there is a clear subarachnoid space between the tumor and normal cord; on contrast-enhanced T1-weighted MR images, the boundary line between the tumor and normal cord is smooth. Otherwise the boundary is ill defined. When most of the boundary was ill defined, even if some parts were well defined, the tumor boundary should be regarded as ill defined (14).

Besides, in our experience, it is not necessary to manage the syrinx associated with the ependymoma. We avoided entering or draining the syrinx during the course of resection because the syrinx would collapse after tumor removal (5). In our series, all the 15 patients with syrinx showed syrinx reduction after surgery.

\section{Short-Term Outcomes}

Generally speaking, a favorable functional outcome could be achieved in most patients. In the early postoperative course, it is reported that $9-67 \%$ of spinal ependymoma patients experienced neurological status aggravation $(4,23,24,28)$. In this series, 25 of the 28 patients $(89.3 \%)$ had stable or improved $\mathrm{mMG}$ grades directly after surgery, and only 3 patients (10.7\%) experienced acute neurological decline after surgery, but all these 3 patients returned to baseline within 1 month of surgery. The neurological decline found in this study is similar to that reported in other spinal ependymoma series. The protection of respiratory function is extremely important during operation. Three of our patients $(10.7 \%)$ had respiratory difficulty after surgery, and underwent tracheostomy and required ventilator assistance. And all these 3 patients recovered their respiratory function before discharge. Every effort should be made to prevent aspiration and pneumonia for patients with lower cranial nerve deficits and respiratory difficulty, which might be fatal for these patients.

Regarding the transition of different preoperative symptoms, an interesting finding of this study is that neck pain was relieved in all the 13 patients $(100.0 \%)$ in a short term after surgery, followed by headache (5 of $6,83.3 \%$ ), lower cranial nerve deficits ( 3 of $4,75.0 \%$ ), numbness of limbs (50.0\%), dizziness
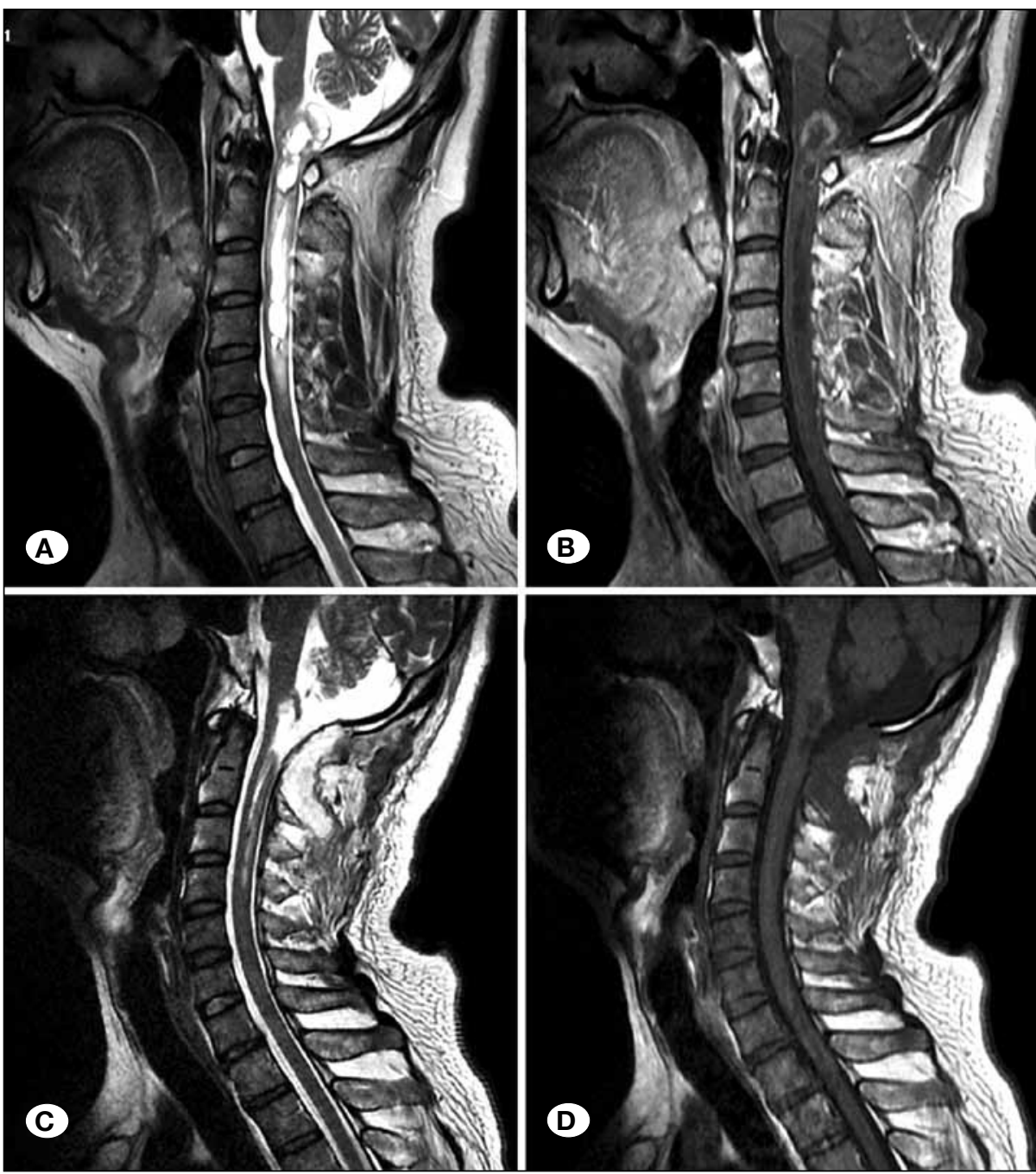

Figure 4: Pre- and postoperative MRI scans of patient No. 27.

Preoperative sagittal T2-weighted MRI (A) and T1-weighted imaging with contrast enhancement (B) showing the ependymoma from medulla oblongata rostrally to the second cervical vertebra caudally with an ill-defined tumor boundary. MRI scans at one week after surgery illustrating subtotal removal of the lesion (C, D). 
(50.0\%), and motor weakness (35.7\%). Therefore, among the three most common preoperative manifestations (motor deficits, neck pain and numbness) for ICE, the improvement rate of neck pain was significantly higher than that of motor deficits $(p=0.001)$, and numbness of limbs $(p=0.005)$. In others words, for patients whose main preoperative symptoms were neck pain, a better clinical outcome could be expected directly after surgery.

\section{Long-Term Outcomes}

An excellent outcome was achieved in our series. After a mean follow-up duration of 49.6 months, compared to the preoperative $\mathrm{mMG}$, the $\mathrm{mMG}$ at long-term follow-up improved in $89.3 \%$ of patients, stabilized in $10.7 \%$, and no one deteriorated. The long-term neurological function was significantly better than that of the preoperative mMGs $(p<0.001)$ and the mMGs at discharge $(p<0.001)$. Therefore, our results showed that operation could lead to better neurological functions in the long run for ICE patients. Compared with previous studies, our series seemed to have a better outcome, as the rate of improvement and stabilization ranged from $81.6 \%$ to $95.5 \%$ in previous studies $(2,6,11,15$, 16).

With respect to the transition of different symptoms, among the three most common preoperative manifestations, neck pain is also most likely to relieve (100.0\%), followed by motor weakness $(78.6 \%)$ and numbness of limbs $(75.0 \%)$. Therefore, compared with neck pain, motor deficits and numbness are relatively difficult to recover.

\section{Prognostic Factors}

Most previous studies agree that GTR is a predictor for a better outcome $(2,3,6,17,24)$. And some authors concluded that poor preoperative status is a significant predictor of a poor outcome (15). Li et al. indicated that the length of spinal ependymoma is a significant factor and patients with longer tumor had worse results (16). Besides, most authors believe adjuvant radiotherapy didn't confer a survival benefit $(14,17)$.

In our study, GTR is found to be a significant factor leading to a better function outcome in a short-term after surgery, which is similar to previous studies. The other factors are not significantly associated with clinical outcome, such as gender, age, syrinx and tumor length. However, as there is no patient with function deterioration in the long-term follow-up, the analysis of prognostic factor cannot be performed.

\section{Study Limitations}

The present study has several limitations. First, it is a retrospective research with limitations inherent to the study design. Second, because the rarity of ICE, a relatively small number of patients was enrolled. This limited the statistical analysis. Because of the small number of patients, we did not analyze the effect of histology (high grade and low grade) and postoperative radiotherapy on the outcomes.

\section{CONCLUSION}

Gross total resection of ICE could be performed in most patients, especially for those with well-defined tumor boundaries. GTR leaded to a better outcome in the short term after surgery when it is safe to conduct. A favorable functional outcome could be achieved for most ICE patients in the long term. Compared with motor weakness and numbness of limbs, neck pain has a greater possibility to improve after surgery.

\section{- ACKNOWLEDGEMENT}

This study was granted by National Key Technology Research and Development Program of the Ministry of Science and Technology of China (grant number: 2013BAI09B03).

\section{REFERENCES}

1. Aghakhani N, David P, Parker F, Lacroix C, Benoudiba F, Tadie M: Intramedullary spinal ependymomas: Analysis of a consecutive series of 82 adult cases with particular attention to patients with no preoperative neurological deficit. Neurosurgery 62:1279-1285; discussion 1285-1286, 2008

2. Ahyai $A$, Woerner $U$, Markakis $E$ : Surgical treatment of intramedullary tumors (spinal cord and medulla oblongata). Analysis of 16 cases. Neurosurg Rev 13:45-52, 1990

3. Bostrom A, von LM, Hartmann W, Pietsch T, Feuss $M$, Bostrom JP, Schramm J, Simon M: Surgery for spinal cord ependymomas: Outcome and prognostic factors. Neurosurgery 68:302-308; discussion 309, 2011

4. Chen P, Sui M, Ye J, Wan Z, Chen F, Luo C: An integrative analysis of treatment, outcomes and prognostic factors for primary spinal anaplastic ependymomas. J Clin Neurosci 22:976-980, 2015

5. Deng X, Wang K, Wu L, Yang C, Yang T, Zhao L, Yang J, Wang G, Fang J, Xu Y: Intraspinal hemangioblastomas: Analysis of 92 cases in a single institution. J Neurosurg Spine 21:260269, 2014

6. Ferrante L, Mastronardi L, Celli P, Lunardi P, Acqui M, Fortuna A: Intramedullary spinal cord ependymomas-a study of 45 cases with long-term follow-up. Acta Neurochir (Wien) 119:7479, 1992

7. Figueiredo N, Brooks N, Resnick DK: Evidence-based review and guidelines for the management of myxopapillary and intramedullary ependymoma. J Neurosurg Sci 57:327-341, 2013

8. Gavin QD, Farooqi N, Pigott TJ, Findlay GF, Pillay R, Buxton $\mathrm{N}$, Jenkinson MD: Outcome predictors in the management of spinal cord ependymoma. Eur Spine J 16:399-404, 2007

9. Guyotat J, Metellus P, Giorgi R, Barrie M, Jouvet A, FevreMontange $M$, Chinot $O$, Durand $A$, Figarella-Branger D: Infratentorial ependymomas: Prognostic factors and outcome analysis in a multi-center retrospective series of 106 adult patients. Acta Neurochir (Wien) 151:947-960, 2009

10. Hanbali F, Fourney DR, Marmor E, Suki D, Rhines LD, Weinberg JS, McCutcheon IE, Suk I, Gokaslan ZL: Spinal cord ependymoma: Radical surgical resection and outcome. Neurosurgery 51:1162-1172; discussion 1172-1174, 2002

11. Hsu W, Pradilla G, Constantini S, Jallo GI: Surgical considerations of spinal ependymomas in the pediatric population. Childs Nerv Syst 25:1253-1259, 2009 
12. Jenkinson MD, Simpson C, Nicholas RS, Miles J, Findlay GF, Pigott TJ: Outcome predictors and complications in the management of intradural spinal tumours. Eur Spine J 15:203210, 2006

13. Klekamp J: Spinal ependymomas. Part 1: Intramedullary ependymomas. Neurosurg Focus 39:E6, 2015

14. Lee SH, Chung CK, Kim CH, Yoon SH, Hyun SJ, Kim KJ, Kim ES, Eoh W, Kim HJ: Long-term outcomes of surgical resection with or without adjuvant radiation therapy for treatment of spinal ependymoma: A retrospective multicenter study by the Korea Spinal Oncology Research Group. Neurooncol 15:921929, 2013

15. Li D, Hao SY, Wu Z, Jia GJ, Zhang LW, Zhang JT: Intramedullary medullocervical ependymoma-surgical treatment, functional recovery, and long-term outcome. Neurol Med Chir (Tokyo) 53:663-675, 2013

16. Li TY, Chu JS, Xu YL, Yang J, Wang J, Huang YH, Kwan AL, Wang GH: Surgical strategies and outcomes of spinal ependymomas of different lengths: Analysis of 210 patients. J Neurosurg Spine 21:249-259, 2014

17. Lin Y, Smith ZA, Wong AP, Melkonian S, Harris DA, Lam S: Predictors of survival in patients with spinal ependymoma. Neurol Res 37:650-655, 2015

18. McCormick PC, Torres R, Post KD, Stein BM: Intramedullary ependymoma of the spinal cord. J Neurosurg 72:523-532, 1990

19. Mehta GU, Asthagiri AR, Bakhtian KD, Auh S, Oldfield EH, Lonser RR: Functional outcome after resection of spinal cord hemangioblastomas associated with von Hippel-Lindau disease. J Neurosurg Spine 12:233-242, 2010

20. Nagasawa DT, Smith ZA, Cremer N, Fong C, Lu DC, Yang I: Complications associated with the treatment for spinal ependymomas. Neurosurg Focus 31:E13, 2011
21. Rodriguez D, Cheung MC, Housri N, Quinones-Hinojosa A, Camphausen K, Koniaris LG: Outcomes of malignant CNS ependymomas: An examination of 2408 cases through the Surveillance, Epidemiology, and End Results (SEER) database (1973-2005). J Surg Res 156:340-351, 2009

22. Safaee M, Oh MC, Mummaneni PV, Weinstein PR, Ames CP, Chou D, Berger MS, Parsa AT, Gupta N: Surgical outcomes in spinal cord ependymomas and the importance of extent of resection in children and young adults. J Neurosurg Pediatr 13:393-399, 2014

23. Schebesch KM, Mueller S, Wendl C, Brawanski A, Riemenschneider MJ, Proescholdt M: Recurrence rates and functional outcome after resection of intrinsic intramedullary tumors. Clin Neurol Neurosurg 134:60-66, 2015

24. Schwartz TH, McCormick PC: Intramedullary ependymomas: Clinical presentation, surgical treatment strategies and prognosis. J Neurooncol 47:211-218, 2000

25. Vandertop WP: Spinal cord ependymoma: Radical surgical resection and outcome. Neurosurgery 53:246; author reply 246-247, 2003

26. Vitanovics D, Balint K, Hanzely Z, Banczerowski P, Afra D: Ependymoma in adults: Surgery, reoperation and radiotherapy for survival. Pathol Oncol Res 16:93-99, 2010

27. Yang T, Wu L, Yang C, Deng X, Xu Y: Clinical features and long-term outcomes of intraspinal ependymomas in pediatric patients. Childs Nerv Syst 30:2073-2081, 2014

28. Yuce I, Sade R, Calikoglu C, Ogul H, Kantarci M: Anaplastic ependymoma of spinal cord presented with low back pain. Spine J 15:1894, 2015 